\begin{tabular}{|c|l|}
\hline Title & $\begin{array}{l}\text { Regulation of matrix metall loproteinase 13 and tissue inhibitor of matrix metalloproteinase 1 gene expression by } \\
\text { WNT 3A and bone morphogenetic protein-2 in osteoblastic differentiation }\end{array}$ \\
\hline Author(s) & A iko, Nakashima; Masato, Tamura \\
\hline Citation & $\begin{array}{l}\text { Frontiers in Bioscience, 11, 1667-1678 } \\
\text { https://doi.org/10.2741/1912 }\end{array}$ \\
\hline Issue Date & 2006-05-01 \\
\hline Doc URL & http://hdl.handle.net/2115/8432 \\
\hline Type & article (author version) \\
\hline File Information & RevisedMStamura.pdf \\
\hline
\end{tabular}

Instructions for use 


\title{
REGULATION OF MATRIX METALLOPROTEINASE-13 AND TISSUE INHIBITOR OF MATRIX METALLOPROTEINASE-1 GENE EXPRESSION BY WNT3A AND BONE MORPHOGENETIC PROTEIN -2 IN OSTEOBLASTIC DIFFERENTIATION
}

\author{
Aiko Nakashima and Masato Tamura \\ Department of Biochemistry and Molecular Biology, Graduate School of Dental Medicine, Hokkaido University, \\ Sapporo, 060-8586, Japan \\ TABLE OF CONTENTS \\ 1. Abstract \\ 2. Introduction \\ 3. Materials and Methods \\ 3.1 Cell Cultures \\ 3.2 Establishment of stable transfected C2C12 cells \\ 3.3 Reverse transcriptase-polymerase chain reaction (RT-PCR) \\ 3.4 Quantitative real time PCR \\ 3.5 Measurement of secreted MMP-13 activity \\ 3.6 Reagents \\ 3.7 Statistical Analysis \\ 4. Results \\ 4. 1 Characterization of Wnt3a or Wnt5a over-expressing C2C12 cells \\ 4. 2 MMP and TIMP mRNA expressions and their regulation by BMP-2 and Wnt \\ 4. $3 M M P-13$ activity in culture supernatant \\ 4. 4 MEPE, osteocalcin, ALP, and Runx2 mRNA expressions and their regulation by BMP-2 and Wnt \\ 5. Discussion \\ 6. Acknowledgements \\ 7. References
}

\section{ABSTRACT}

During bone remodeling, degradation of skeletal connective tissue is regulated, at least in part, by the balance between matrix metalloproteinases (MMPs) and tissue inhibitors of matrix metalloproteinase (TIMPs), their natural inhibitors. Recently, the Wnt signaling pathway has been demonstrated to play a crucial role in the regulation of bone formation. Here, we investigated a potential role for Wnt signaling and functional cross-talk with bone morphogenetic protein (BMP)-2 in mRNA expression of MMPs, TIMPs and bone matrix proteins in pluripotent C2C12 cells. To assess the functional contribution of Wnt signaling, we have generated C2C12 cell lines stably over-expressing Wnt3a or Wnt5a, and then treated these cells with BMP-2 for 24 h. In these cultures, MMP-13 mRNA expression was induced by BMP-2 in Wnt3a over-expressing C2C12 (Wnt3a-C2C12) cells but not in either Wnt5a over-expressing C2C12 (Wnt5a-C2C12) cells or vehicle-transfected C2C12 cells. MMP-13 mRNA was induced in these cells by addition of BMP-2 for $12 \mathrm{~h}$ and the enhancement lasted up to $48 \mathrm{~h}$. These effects were observed in a dose-dependent manner. Enzymatic activity of MMP-13 also induced in Wnt3a-C2C12 cells by addition of BMP-2. However, membrane type-1 matrix metalloproteinase (MT1-MMP) and MMP-2 mRNA expression was not affected by either Wnt3a or BMP-2. In contrast, TIMP-1 mRNA expression was suppressed by BMP-2 in Wnt3a-C2C12 cells but not in Wnt5a-C2C12 cells. Our results show that expression of MMP-13 and TIMP-1 is regulated by Wnt signaling combined with BMP-2 in osteoblastic differentiation, and this signaling may in part mediate MMP-13 and TIMP-1 production during bone formation and/or remodeling.

\section{INTRODUCTION}

Bone formation is a complex process that involves the recruitment of progenitor cells, their proliferation and differentiation into osteoblasts, resulting in the secretion of abundant bone extracellular matrix (ECM) proteins that coordinate the mineralization process $(1,2)$. The major bone matrix protein produced by these cells is type I collagen. Additionally, non-collagenous matrix proteins have been identified that influence the processes of bone formation, remodeling and repair. The non-collagenous matrix proteins include osteocalcin, osteopontin, bone sialoprotein, matix extracellular phosphoglycoprotein (MEPE), matrix glutamic acid protein, osteonectin, biglycan, and so on (2). The exact functions of many of these ECM proteins have not yet been delineated, although, for most, targeted deletion of these genes in mice has provided evidence of a role in regulating mineralization events in bone remodeling (2). The matrix metalloproteinases (MMPs) constitute a multigene family of over twenty secreted and cell surface enzymes that process or degrade numerous ECM components (3). These proteinases are stored in the ECM in an inactive form, and their activities are regulated by specific activators and inhibitors (4). In 
bone tissue, osteoblastic expression of several MMPs including MMP-1, MMP-2, MMP-3, MMP-9 (gelatinase B), MMP-13 (collagenase 3), MMP-14 and membrane type-1 matrix metalloproteinase (MT1-MMP) have been reported (5-7). Certain cytokine and growth factors may regulate MMPs and related factors such as tissue inhibitors of matrix metalloproteinases (TIMPs) in osteoblasts in order to degrade bone ECM proteins in addition to their stimulating function on osteoclastic bone resorption (7, 8). Moreover, the MMPs have been implicated in the degradation of many ECM proteins not only in the bone resorption process but also in stages of the developmental program of bone such as endochondral bone formation, programmed cell death, cell migration, and invasion during these morphogenic processes (9, 10).

MMP-13 belongs to the family of MMPs, which are responsible for degrading components of intact collagen fibrils, whereas gelatinases degrade collagen fragments generated by prior collagenase digestion (11). Since MMP-13 appears to be a major regulator of collagen turnover, this enzyme is widely present in normal cells such as osteoblasts, hypertrophic chondrocytes, fibroblasts and smooth muscle cells as well as in pathological tissues such as chodrocytes in rheumatoid arthritis or osteaorthritis (12). In bone tissue, MMP-13 is synthesized by osteoblasts and osteocytes, and ECM degradation by MMP-13 has been associated with bone remodeling, endochodral bone formation, bone repair, and parathyroid hormone-induced bone resorption (12). In situ hybridization analyses revealed expression of MMP-13 during the onset of bone formation in later embryonic mouse tissues (13). The role of MMP-13 in bone degradation is further evidenced by the finding that homologous mutation of the collagenase cleavage site in the Col a1 gene in mutant mice results in diminished parathyroid hormone (PTH)-induced bone resorption and thicker bones (14). Like most other MMPs, MMP-13 is regulated by various bone-remodeling agents; PTH, 1,25-dihydroxyvitamin $D_{3}$, prostaglandin (PG) $E_{2}$, interleukin (IL)-1 $\beta$, and tumor necrosis factor (TNF)- $\alpha$ and growth factors such as fibroblast growth factor (FGF) 2, platelet-derived growth factor (PDGF) BB, insulin like growth factors (IGFs) and transforming growth factor (TGF) $\beta 1$ at the level of transcription (8, 15-17). Mechanical stimuli also regulates MMP-13 mRNA expression (18). Various bone-resorbing agents, such as PTH, increase collagen degradation by increasing MMP production and inhibiting collagen synthesis (19). Similar to osteocalcin, MMP-13 gene expression increases during osteoblastic differentiation $(20,21)$ and is transcriptionally regulated by Runx2, a runt domain-binding transcription factor found in osteoblasts, during this process.

Osteoblasts also synthesize TIMP- 1, -2, and -3 , and their expressions are regulated by various bone-remodeling agents such as FGF2 and IGFs (22, 23). Mice specifically overexpressing TIMP-1 in osteoblasts have been generated to investigate the role of MMPs in bone in vivo (24). These mice displayed increased trabecular bone volume and decreased bone turnover, providing evidence of the role played by the MMPs in bone remodeling and balance (24). Inducers of bone formation may increase collagen content by decreasing its degradation by MMPs or by enhancing collagen synthesis. Therefore, it appears that bone formation is associated with inhibition of MMP expression or stimulation of TIMP expression, whereas bone resorption is associated with stimulation of MMP synthesis or inhibition of TIMP expression.

MEPE was one of the bone matrix proteins identified from cDNA as a tumor-derived phosphaturic factor in oncogenic hypophosphatemic osteomalacia (25) and this cDNA coded for a matrix protein consisting of a serine/glycine-rich secreted peptide that contained numerous potential phosphorylation sites and one RGD motif (26). This protein is a member of the SIBLING (Small integrin-binding ligand, $\mathrm{N}$-linked glycoprotein) family of matrix proteins, which includes MEPE, bone sialoprotein, dentin matrix protein 1, dentin sialophosphoprotein, enamelin and osteopontin, expressed in bones and/or teeth (27). The tissue distribution of this mRNA is bone specific and highly expressed in osteoblasts and osteocytes (26). Furthermore, targeted disruption of the MEPE gene in mice results in increased bone formation and bone mass (28). Although MEPE is perhaps involved in the regulation of bone metabolism in vivo, regulation of the expression of this gene during osteoblastic differentiation has not yet been identified.

Recently, a loss-of-function mutation or a Gly171-to-Val substitution mutation in lipoprotein receptor-related protein (LRP) 5 was found to be associated with the autosomal recessive disorder osteoporosis-pseudoglima syndrome or a high-bone-mass phenotype, respectively $(29,30)$. LRP5 is one of the co-receptors of Wnts, a large family of secreted proteins that regulate a huge variety of developmental processes, cell differentiation, proliferation and migration. Signaling is initiated by Wnt ligand binding to two receptor molecules, Frizzled protein, LRP 5 and 6 (31). Two types of Wnt proteins have been identified; one class of which is the $\beta$-catenin-dependent canonical Wnts such as Wnt1, Wnt2, Wnt3 and Wnt3a. The other class is the so-called " noncanonical" Wnts such as Wnt4, Wnt5a, Wnt5b, Wnt6 and Wnt7a which are independent of or inhibit $\beta$-catenin signaling (32). According to the current model of canonical Wnt action, in cells lacking Wnt signal, glycogen synthase kinase (GSK)-3 $\beta$ phosphorylates $\beta$-catenin, inducing rapid degradation of $\beta$-catenin via the ubiquitin/proteosome pathway. Conventional Wnt signaling causes stabilization of $\beta$-catenin and its accumulation in a complex with the 
transcription factor lymphoid enhancer factor $1 / \mathrm{T}$ cell factor (Lef1/Tcf) that regulates expression of target genes such as c-myc and cyclin D1 (32). Phenotypes of loss of function or substitution mutations of LRP5 indicated that canonical Wnt signaling may modulate regulation of bone mass and bone formation $(29,30)$.

Bone morphogenetic proteins (BMPs), members of the TGF- $\beta$ superfamily, regulate the proliferation, differentiation and apoptosis of various types of cells and organs not only in embryonic development but also in postnatal physiological function (33). Among these, BMP-2 alone is sufficient to induce ectopic bone formation when it is implanted into the tissues of rodents and to trigger osteoblast differentiation and up-regulate the expression of most genes encoding osteoblastic phenotype-related proteins such as osteocalcin in vitro (34). We previously examined that Wnt3a down-regulates expression of the BMP-2-response gene, Id1, and this suppression is mediated by a 29-bp GC rich region of the BMP-2 responsive element in the Id1 gene promoter (Nakashima et al., manuscript in preparation). Thus, our previous findings indicated that Wnt signaling links BMP-target gene expression and illustrated the functional role of Wnt in BMP-2-induced osteoblast differentiation. However it remains unclear whether Wnt signaling is directly coupled to expression of MMPs, TIMPs and matrix proteins with participation of BMP-2, and thus regulates osteoblastic differentiation.

In the present study, we used stimulatory Wnt3a and inhibitory Wnt5a canonical Wnt-expressing pluripotent C2C12 cells (Wnt3a-C2C12 cells and Wnt5a-C2C12 cells), and demonstrated that expression of both MMP-13 and MEPE were dramatically induced by BMP-2 in Wnt3a-C2C12 cells but not in either Wnt5a-C2C12 cells or vehicle-C2C12 cells. Additionally, TIMP1 expression was diminished by BMP-2 in Wnt3a-C2C12 cells but not in either Wnt5a-C2C12 cells or vehicle-C2C12 cells. We provide evidence for divergent regulation of MMP-13 and TIMP-1 expression by BMP-2 combined with canonical Wnt signaling in osteoblastic differentiation.

\section{MATERIALS AND METHODS}

\subsection{Cell Cultures}

The mouse myoblast cell line C2C12 (Cell Systems. Kirkland, WA) and MC3T3-E1 cells (RIKEN Cell Bank, Tsukuba, Japan) (35) were cultured in $\alpha$-MEM (Sigma, St. Louis, MO) containing $100 \mu \mathrm{g} / \mathrm{ml}$ of kanamysin (Meiji, Tokyo, Japan) supplemented with $10 \%$ fetal bovine serum (FBS) at $37^{\circ} \mathrm{C}$ in $100-\mathrm{mm}$ cell culture dishes (Corning, Corning, NY) in a humidified atmosphere of $5 \% \mathrm{CO}_{2}$ in air.

\section{2 Establishment of stable transfected C2C12 cells \\ For establishment of stable transfected C2C12 cells, complementary DNA (cDNA) constructs}

including human full-length Wnt3a or Wnt5a cDNA in pUSEamp under the control of the CMV promoter were purchased from Upstate Biotechnology (Lake Placid, NY). Cells were plated 1 day before transfection in a $\alpha$-MEM at a density of $5 \times 10^{4}$ cells per well of a 24-well plate. The cells were transfected with Wnt3a-pUSEamp, Wnt5a-pUSEamp or empty vector using Lipofectamine 2000 (Invitrogen) according to the manufacturer's protocol. Two days after transfection, medium was changed to $\alpha$-MEM containing neomycin/Geneticin (G418) (Promega, Madison, WI) at $0.1 \mu \mathrm{g} / \mathrm{ml}$. The cells were passaged, and the clones were selected in $\alpha$-MEM supplemented with G418 and $10 \%$ FBS. To rule out the possibility of clonal variation, we characterized at least three independent clones for each stable transfection. We denoted these cell lines Wnt3a-C2C12 cells, Wnt5a-C2C12 cells and vehicle-C2C12 cells, respectively.

3.3 Reverse transcriptase-polymerase chain reaction (RT-PCR)

Total RNA was extracted from the cells at the indicated time points using

Isogen (Nippongene, Toyama, Japan) and treated with RNase-free DNase (Qiagen) to remove any contaminating genomic DNA according to the manufacturer's protocol. Complementary DNA was synthesized with Omniscript reverse transcriptase (Qiagen) using a $(\mathrm{dT})_{15}$ primer $(1 \mu \mathrm{M})$ according to the manufacturer's instructions. Amplification of cDNA by PCR was performed under the following conditions: $94^{\circ} \mathrm{C}$ for $30 \mathrm{sec}$, annealing temperature shown in Table 1 for $30 \mathrm{sec}$, and $72^{\circ} \mathrm{C}$ for $1 \mathrm{~min}$ followed by a final heating at $72^{\circ} \mathrm{C}$ for $10 \mathrm{~min}$. The primer sequences used for PCR amplification were designed based on cDNA sequences as indicated in Table $1(11,32,36-46)$. Amplified PCR products were subcloned into the pGEM $^{\circledR}$-T vector (Promega, Madison, WI) using the pGEM $^{\circledR}$-T Vector System II and the sequences of the subcloned cDNAs were checked by a DNA sequencer (Prism 310, Applied Biosystems, Foster city, CA). All the primers were synthesized by Hokkaido System Science (Sapporo, Japan). Amplified products were visualized by agarose gel electrophoresis after staining with ethidium bromide.

\subsection{Quantitative real time PCR}

Quantification of MMP-13 or TIMP-1 mRNA was performed using an ABI Prism 7000 sequence detection system (Applied Biosystems) as previously described (47). In brief, one $\mu \mathrm{g}$ of each RNA sample was subjected to reverse transcription using the omniscript RT kit (Qiagen) and RNase-free DNase Set (Qiagen) in a total volume of $20 \mu \mathrm{l}$. Then, $2.5 \mu \mathrm{l}$ of the reaction mixture were incubated with the double-stranded DNA dye SYBR Green I (Qiagen) in a total volume of $25 \mu \mathrm{l}$. The primers used are: MMP-13, 5'-ACAGGGGCTAAGGC AGAAAT -3' (forward) and 5'- GTCTCAAAAGGGCGACTGAC-3' (reverse) 
TIMP-1, 5'-CGAATCAACGAGACCACCTT-3' (forward) and 5'-CATTTCCCACAGCCTTGAAT-3' (reverse) $\beta$-actin, 5'- GATCATTCTCCTCCTGAGC -3' (forward) and 5'-ACATCTGCTGGAAGGTGGAC -3' (reverse). All reactions were run in with a hot start pre-incubation step of $10 \mathrm{~min}$ at $95^{\circ} \mathrm{C}$, following by cycles of $15 \mathrm{sec}$ at $95^{\circ} \mathrm{C}, 1 \mathrm{~min}$ at $60^{\circ} \mathrm{C}$ and fluorescentintensity was measured at a specific acquisition temperature for each gene. We performed these experiments using samples from at least three different cell preparations and quantification of mRNA was confirmed using the same cell sample at least in triplicate. The amount of template was quantified using secondary-derivative-maximum program as outlined in the manufacturer's technical bulletin. Measured individual mRNA Level was then normalized to mRNA level of $\beta$-actin.

\subsection{Measurement of secreted MMP-13 activity}

Wnt3a-C2C12 cells, Wnt5a-C2C12 cells and vehicle-C2C12 cells were seeded at the density of $1 \mathrm{X} 10^{6}$ cells on a $100-\mathrm{mm}$ cell culture dish in $10 \mathrm{ml}$ of culture medium and cultured for $24 \mathrm{~h}$. Then, $300 \mathrm{ng} / \mathrm{ml}$ of BMP-2 or vehicle was added in $\alpha$-MEM supplemented with $10 \%$ FBS, after which cells were cultured for $48 \mathrm{~h}$. After medium was changed to serum-free $\alpha$-MEM with $300 \mathrm{ng} / \mathrm{ml}$ of BMP-2, cells were cultured for a further $24 \mathrm{~h}$. Then, the culture supernatant of each dish was collected, centrifuged to remove cell debris, and stored at $-20^{\circ} \mathrm{C}$. The culture supernatant of each dish was collected and $20 \mathrm{X}$ concentrated samples were prepared. MMP-13 activity was determined at room temperature for 30 min using an MMP-13 activity assay kit (Exalpla Biologicals, Waterton, MA) by synthetic fluorogenic peptide as a substrate. Fluorescence readings ( $\boldsymbol{A}_{\text {excitation }}=365 \mathrm{~nm}$ and $\boldsymbol{X}_{\text {emission }}=450 \mathrm{~nm}$ ) were taken and a standard curve created by plotting the increase in fluorescence versus concentration of recombinant truncated form of human MMP-13 as a standard. The standard curve was used to calculate the active enzyme concentration in the conditioned media. All samples were assayed in triplicate.

\subsection{Reagents}

Recombinant human BMP-2 (48) was kindly supplied from Astellas Pharmaceutical (Tokyo, Japan). Cycloheximide and dichlororibofuranosyl benzimidazole (DRB) were purchased from Sigma Chemical Co. (St Louis, MI).

\section{7 Statistical analysis}

All experiments were repeated three to four times and representative results are presented. The data are reported as the mean \pm standard deviation, and were analyzed by the Student's t-test, where values of $\mathrm{p}<$ 0.05 were considered significant.

\section{RESULTS}

4..1 Characterization of Wnt3a or Wnt5a over-expressing C2C12 cells

To examine a potential role for Wnt canonical signaling and the functional contribution of BMP-2 to MMP, TIMP and matrix protein mRNA expression in mesenchymal cell differentiation, we generated a pluripotent $\mathrm{C} 2 \mathrm{C} 12$ cell line stably expressing Wnt3a or Wnt5a. C2C12 cells are a myoblastic cell line and are a well-characterized model system which have been reported to differentiate not only into myotubes but also into osteoblasts, depending upon the specific culture conditions, when incubated in the presence of BMPs for 48-72 h (49). These culture conditions were previously shown to give rise to cells that expressed numerous mRNAs characteristic of osteoblasts including bone matrix proteins such as osteocalcin and osteopontin as well as transcription factors involved in osteoblastic differentiation such as Runx2 (50). C2C12 cells were transfected with the Wnt3a expression plasmid to activate canonical Wnt signaling or the Wnt5a expression plasmid to inhibit canonical Wnt signaling, and then selected using G418 to establish cell lines (Wnt3a-C2C12, Wnt5a-C2C12 cells). To confirm activation or suppression of canonical Wnt signaling in these cells, we transfected with Topflash, the reporter plasmid that carries six tandem repeats of the Lef1/Tcf binding site. The promoter activity of Topflash is enhanced in Wnt3a-C2C12 cells and suppressed in Wnt5a-C2C12 cells (Nakashima et al., manuscript in preparation).

In these cultures, we added BMP-2 at 300 $\mathrm{ng} / \mathrm{ml}$ for $24 \mathrm{~h}$, and then performed RT-PCR analysis of total RNA isolated from these cells to examine Wnt3a or Wnt5a mRNA expression. While vehicle-transfected C2C12 cells did not produce any detectable Wnt3a or Wnt5a expression, Wnt3a-C2C12 cells or Wnt5a-C2C12 cells expressed high levels of Wnt3a or Wnt5a mRNA, respectively, detected by RT-PCR analysis (Figure 1A). With the addition of BMP-2, Wnt3a mRNA not but Wnt5a mRNA expression was slightly increased (Figure 1A). Wnt3a-C2C12 cells exhibited distinct morphological differences compared with Wnt5a-C2C12 or vehicle-C2C12 cells (Fig. 1B). The cells were more elongated and, upon visual inspection, appeared to be denser. BMP-2 treatment induced morphologic changes from a spindle-like, elongated shape to smaller, cuboidal cells in Wnt3a-C2C12 cells as well as in Wnt5a-C2C12 or vehicle-C2C12 cells (Figure 1B).

4. 2 MMP and TIMP mRNA expressions and their regulation by BMP-2 and Wnt.

We first examined whether Wnt signaling and BMP-2 treatment specifically modulates MMP or TIMP gene expression using C2C12 cells stably overexpressing Wnt3a or Wnt5a. To these cultures, we added BMP-2 at $300 \mathrm{ng} / \mathrm{ml}$ for $24 \mathrm{~h}$, and then performed RT-PCR analysis on total RNA isolated from 
these cells. The MMP-13 transcript could not be detected in Wnt3a-C2C12 cells, Wnt5a-C2C12 cells or vehicle-C2C12 cells; however BMP-2 dramatically induced MMP-13 mRNA expression in Wnt3a-C2C12 cells but not in Wnt5a-C2C12 cells nor in vehicle-C2C12 cells (Figure 2A). MMP-2 and MT1-MMP expression were detected in vehicle-C2C12 cells without BMP-2 treatment. There was no detectable difference in the amount of MMP-2 or MT1-MMP mRNA with either Wnt signaling or BMP-2 treatment in these cultures (Figure 2A), indicating that Wnt3a and BMP-2 specifically induced MMP-13 in C2C12 cells. MMP-1 and MMP-8 expression could not detect during all days of cultures (data not shown). Although TIMP-1 mRNAs were expressed in almost equal amounts in Wnt3a-C2C12 cells and Wnt5a-C2C12 cells as well vehicle-C2C12 cells, TIMP-1 expression was dramatically abolished by BMP-2 in Wnt3a-C2C12 cells not but Wnt5a-C2C12 cells or vehicle-C2C12 cells. In contrast to TIMP-1, TIMP-2 expression was not influenced by Wnt overexpression or BMP-2 treatment (Figure 2A). As an internal control, the mRNA level of the housekeeping gene $\beta$-actin was found not to be altered by Wnt overexpression or the addition of BMP-2. To substantiate these findings, we performed real-time PCR (Figure 2B). The MMP-13 mRNA copies were dramatically increased about 10-fold within 24 h by BMP-2 compared to no addition in Wnt3a-C2C12 cells. On the other hand, BMP-2 failed to change the number of MMP-13 mRNA copies in vehicle-C2C12 cells. Conversely, TIMP-1 mRNA copies were down-regulated to about $10 \%$ by BMP- 2 treatment compared with absence of BMP-2 in Wnt3a-C2C12 cells. In vehicle-C2C12 cells, BMP-2 did not alter TIMP-1 mRNA copies.

In order to confirm the regulation of MMP-13 and TIMP-1 expression by BMP-2 in Wnt3a-C2C12 cells, we performed analyses of time and dose dependency on this regulation. In response to BMP-2 in Wnt3a-C2C12 cells, MMP-13 expression levels began to be up regulated after $24 \mathrm{~h}$ then remained constant up to $72 \mathrm{~h}$, whereas MT1-MMP expression was not influenced by BMP-2 (Figure 3A). Reciprocally, TIMP-1 mRNA in Wnt3a-C2C12 cells began to reduce $6 \mathrm{~h}$ after BMP-2 treatment, then reached undetectable levels by $24 \mathrm{~h}$ and plateauxed thereafter. In vehicle-C2C12 cells, neither MMP-13 nor MT1-MMP expression was altered by BMP-2 (Figure 3A). As shown in Fig. 3B, BMP-2 stimulates MMP-13 expression in Wnt3a-C2C12 cells, producing a significant increase with $300 \mathrm{ng} / \mathrm{ml} \mathrm{BMP-2}$ and further increasing expression with $500 \mathrm{ng} / \mathrm{ml}$. TIMP-1 expression was also reduced from $300 \mathrm{ng} / \mathrm{ml}$ BMP-2 and reached undetectable levels with $500 \mathrm{ng} / \mathrm{ml}$ in Wnt3a-C2C12 cells but not in vehicle-C2C12 cells (Figure 3B). Results shown indicate that the combination with canonical Wnt signaling, such as by Wnt3a and BMP-2, positively or negatively regulates
MMP-13 and TIMP-1 expression in C2C12 cells, respectively.

\section{3 MMP-13 activity in culture supernatant}

Using synthetic fluorogenic peptide as a substrate, we measured the effect of BMP-2 on the production of MMP-13 in C2C12 cells stably expressed Wnt3a or Wnt5a. As shown in Figure 4, MMP-13 activity was low level in Wnt3a-C2C12 cell, Wnt5a-C2C12 cells; however BMP-2 dramatically induced MMP-13 activity in Wnt3a-C2C12 cells but not in Wnt5a-C2C12 cells nor in vehicle-C2C12 cells. These results indicated that the combination with Wnt3a and BMP-2 induces not only MMP-13 mRNA expression but also enzymatic activity of MMP-13.

4. 4 MEPE, osteocalcin, alkaline phosphatase and Runx2 mRNA expressions and their regulation by BMP-2 and Wnt.

We next examined whether Wnt signaling combined with BMP-2 specifically modulates expression of matrix proteins, alkaline phosphatase (ALP) or Runx2 in osteoblastic differentiation (Figure 5). MEPE transcript was not detectable not only in Wnt3a-C2C12 cells but also in Wnt5a-C2C12 cells or vehicle-C2C12 cells. Culturing the Wnt3a-C2C12 cells with BMP-2 dramatically induced MEPE expression (Figure 5) in a similar way to MMP-13 expression as shown in Fig. 2. No induction of MEPE expression was seen in Wnt5a-C2C12 cells nor vehicle-C2C12 cells, indicating that Wnt3a and BMP-2 are required for MEPE mRNA induction in C2C12 cells. Osteoblasts have been known to express osteocalcin, ALP and the transcription factor Runx2 and expression of these genes is induced by BMP-2. Although ALP, osteocalcin and Runx2 mRNA expression was induced by BMP-2 treatment not only in vehicle-C2C12 cells but also in Wnt3a-C2C12 cells and Wnt5a-C2C12 cells, all at very similar expression levels, Wnt3a did not change these levels of mRNA expression (Figure 5). Interestingly, expression of osteocalcin and Runx2 induced by BMP-2 were slightly decreased in Wnt5a-C2C12 cells compared with vehicle-C2C12 cells or Wnt3a-C2C12 cells. In this study, we used PCR primers detected for both type I Runx2 and type II Runx2. To assess expression of the Runx2 type I and type II isoforms, we used type I specific primes (5'-ATGCGTATTCCTGT AGATCCGAGC-3' and 5'-GGTGGTCCGCGATGATC T-3') (47). However, expression of type I Runx2 did not significantly detect in both BMP-2-treated and non-treated cells of Wnt3a-C2C12 cells, Wnt5a-C2C12 cells and vehicle-C2C12 cells in repeated studies (data not shown). These results indicate that Runx2 expression of C2C12 cells treated by BMP-2 is type II Runx2 (47). Murine calvaria-derived osteoblastic MC3T3-E1 cells (35) used as an internal control expressed MEPE, osteocalcin, ALP and Runx2 mRNAs (Figure 5).

Time dependent changes in MEPE 
expression in response to the addition of BMP-2 revealed that expression was induced after 1 day then slightly decreased after 4 day (Figure 6A). This induction is similar to that of the osteocalcin transcript except that osteocalcin expression was induced after 1day and then reached maximal levels by 3 day after BMP-2 treatment in Wnt3a-C2C12 cells as well as vehicle-C2C12 cells. This induction of MEPE mRNA increased dose-dependently with the concentration of BMP-2 (Figure 6B). To further address whether BMP-2 exerted effects at the level of transcription of the MEPE gene in these cells, we used the transcription inhibitor, DRB $(10 \mu \mathrm{g} / \mathrm{ml})$ to block RNA synthesis. DRB reduced the mRNA induction response of MEPE to BMP-2 in these cells (Figure 6C), indicating that BMP-2 might enhance transcription of the MEPE gene. Next, to elucidate the potential role of protein synthesis in the induction of MEPE mRNA by BMP-2 in Wnt3a-C2C12 cells, we used $5 \mu \mathrm{g} / \mathrm{ml}$ of cycloheximide (CHX) to block de novo synthesis of protein. With the addition of cycloheximide, there was no change in the level of up-regulation of MEPE mRNA during a $24 \mathrm{~h}$ culture period with BMP-2 (Figure 6C), indicating that the regulation of MEPE expression in these cells is not dependent upon new protein synthesis.

\section{DISCUSSION}

Wnts have been shown to play important roles in the regulation of many aspects of development, which may include chondrogenesis and osteogenesis (29, 30). Since Wnt3a plays a key role in the development of the axial and appendicular skeleton and appears to regulate stem cell proliferation and differentiation, we sought to explore its effect on cells cultured under osteogenic conditions. In cultured cells, Bain et al. (2003) described that stimulation of canonical Wnt signaling using constitutively active forms of $\beta$-catenin induced the activity of ALP which is one of the early differentiation markers in the pluripotent mesenchymal progenitor cell line C3H10T1/2, and also induced mineralization of the osteoblast-like cell line MC3T3-E1 and participated in BMP-2 mediated signal transduction (52). We also observed ALP activity in Wnt3a-C2C12 cells but not in Wnt5a-C2C12 cells (Nakashima et al., manuscript in preparation). However, we observed that expression of osteocalcin, a marker of late osteoblast differentiation, is not induced in Wnt3a-C2C12 cells without BMP-2. This is consistent with Bain et al. who demonstrated that activated $\beta$-catenin does not induce osteocalcin gene expression in C3H10T1/2 cells (52). In this study, we show that signaling by both canonical Wnt and BMP-2 are needed to induce expression of late osteoblastic differentiation marker genes such as MMP-13 and MEPE and to inactivate TIMP-1 expression. Intriguingly, the synergistic effect of Wnt3a or Wnt5a with BMP-2 on gene transcription occurred without altering expression of Runx2, suggesting that canonical Wnt's actions are independent or downstream of this osteoblast-specific transcription factor (34). This is consistent with recent observations in early events during skeletal development such as limb patterning. The phenotypic abnormalities observed in Wnt-deficient mice occur in the context of normal expression of Runx2, a gene controlling osteogenesis (29), indicating a role for a Runx2-independent pathway in control of osteoblast proliferation and function.

In bone formation, mineral deposition occurs in the final stage of osteoblast differentiation and is associated with maximal osteoblastic expression of osteocalcin and MMP-13 (20, 21, 53). Several in vitro studies have indicated that the clonal cell line, C2C12, when cultured under appropriate conditions, might give rise to cells of the osteoblastic lineage with the addition of BMP-2 (50). Incubating the cells with $300 \mathrm{ng} / \mathrm{ml}$ BMP-2 for $6 \mathrm{~h}$ almost completely inhibited the formation of multinucleated myotubes expressing troponin $\mathrm{T}$ and myosin heavy chain, and induced the appearance of ALP-positive cells and osteocalcin expression $(34,50)$. However, we did not detect MMP-13 transcripts with BMP-2 treatment alone in C2C12 cells. When we used Wnt3a-C2C12 cells, BMP-2 dramatically induced MMP-13 mRNA expression. Various bone-remodeling agents such as PTH, 1,25-dihydroxyvitamin $\mathrm{D}_{3}, \mathrm{PGE}_{2}$, IL-1 $\beta$, and TNF- $\alpha$ and extracellular factors such as FGF2 and TGF- $\beta 1$ have been implicated as modulators of MMP-13 expression in osteoblasts (14-17, 22). MMP-13 mRNA is initially detectable when osteoblasts cease proliferation, increasing during differentiation and mineralization $(20,21)$. Our findings indicate that Wnt canonical signaling such as activated by Wnt3a also plays a role in modulating expression of MMP-13 during osteoblastic differentiation. In other words, it may explain why canonical Wnt signaling may not be sufficient and indicate that a combination of BMP-2 and Wnt3a is required for MMP-13 expression in osteoblastic differentiation. Immunohistochemical studies have shown that MMP-13 is found in areas containing woven bone, such as developing bone and areas of fracture healing (54). Almost no MMP-13 is found in normal, adult bone. Taken together, our culture conditions using BMP-2 treatment on Wnt3a-C2C12 cells may result in activating differentiated osteoblasts to develop new bone.

Osteoblast-derived MT1-MMP has recently been suggested to play an important role in the degradation of bone matrix during the process of bone resorption by proteolytically activating latent MMP-2 (proMMP-2) at the cell surface and degrading TNF- $\alpha$ (1). Several inflammatory cytokines and bone resorbing agents including PTH and 1,25-dihydroxyvitamin $D_{3}$ regulate the expression of MT1-MMP in osteoblast-like cells (55). Although 17-beta-estradiol has no influence on MMP-2 production, inflammatory cytokines such as IL-1 and 
IL-6 also stimulate MMP-2 expression in osteoblasts (8). We demonstrated no regulation of MT1-MMP and MMP-2 expression by canonical Wnt and BMP-2, implying that the potency of induction of these MMPs is closely linked to bone-resorbing activity and not to osteoblastic differentiation.

Degradation of skeletal connective tissue is regulated, at least in part, by the balance between MMPs and TIMPs, their natural inhibitors (1). The balance between MMPs and TIMPs may therefore be a determinant of normal bone turnover, and an imbalance could thus lead to a reduction in the organization of bone structure. TIMP production and expression in osteoblasts are also regulated not only by several inflammatory cytokines and bone resobing agents but also developmentally according to the maturation stage of the osteoblasts. Bord et al. (1999) reported that only occasional low level TIMP-1 expression was detectable in chondrocytes and osteoblasts in heterotopic bone by immunohistochemistry (56). In our study, TIMP-1 expression was reciprocally down-regulated by BMP-2 only in Wnt3a-C2C12 cells. It appears that bone formation during osteoblastic differentiation is associated with a balanced regulation involving stimulation of MMP function due to inhibition of TIMP expression.

Recent studies showed that antibodies to MEPE specifically immunostained highly differentiated osteoblasts in adult bone tissues and MEPE mRNA expression in cultured cells was greatly increased when cells were maintained at confluence in the presence of dexamethasone in order to increase differentiation along the osteoblastic lineage (26). Therefore, this body of evidence indicates that MEPE is a specific marker of the osteoblast. Previously we reported that MEPE expression was down-regulated by FGF2 in osteoblastic cells derived from high-density cultures of primary rat bone marrow stromal cells incubated with dexamethasone, $\beta$-glycerophosphate and ascorbic acid (57). We also showed that suppression of MEPE mRNA expression by FGF2 may require activation of the mitogen activated protein kinase (MAPK) signaling pathway in these cells (57). In our present study, not only BMP-2 alone but also BMP-2 in combination with Wnt3a was found to have inductive effects on MEPE mRNA expression, which opens up the possibility that such canonical Wnt signaling may be a potential positive regulator of osteoblastic differentiation and osteoblastic activity in bone tissue. Moreover, MMP-13 and MEPE may play a role during matrix mineralization and bone formation, processes regulated by Wnt3a and BMP-2.

Several studies have shown that cooperation between TGF- $\beta$ superfamily members, including BMPs, and Wnt signaling pathways, plays a role in controlling certain developmental events (32, 33). Signaling by BMPs is initiated following their binding to two types of serine/threonine kinase receptors and Smad proteins have been identified to play critical roles in the intracellular signaling of BMPs (33). The receptor Smads (R-Smads), consisting of Smad1, 2, 3, 5 and 8, are directly phosphorylated by type I receptors, and then form complexes with the Co-Smad, Smad4, and move into the nucleus, where they bind to the regulatory regions of the target genes and regulate their expression (33). The Wnt pathway is quite distinct from that of the TGF- $\beta$ superfamily. Conventional Wnt signaling causes stabilization of $\beta$-catenin and its accumulation in a complex with Tcf/Lef1 that regulates expression of target genes $(29,32)$. It has been shown that Smads interact with Tcf/Lef1 and that specific DNA binding elements are required for synergistic activation by TGF- $\beta$ superfamily members and Wnt pathway activators (58). Our present results suggest the possibility that promoters of the MMP-13 or MEPE genes might interact with Smads in cooperation with $\beta$-catenin/ Tcf/Lef1, and then these complexes might be able to induce expression of these genes. Furthermore, our results point to the possibility that TIMP-1 gene expression also mediates interactions of the $\beta$-catenin/Lef1/Tcf transcriptional complex. It has been reported that BMP-2 activates not only Smad proteins but also MAPK and phosphoinositide 3-kinase to induce their respective intracellular signals (59). We cannot rule out the possibility that MAPK and/or PI3K are involved in the effects of BMP-2 in combination with canonical Wnt signaling in the expression of MMP-13, TIMP-1 and MEPE. Therefore, future detailed analysis will be necessary to address the molecular mechanisms involved in such regulations.

In conclusion, we present here findings demonstrating that signaling of both canonical Wnt and BMP-2 are needed to activate expression of late genes such as MMP-13 and MEPE and to inactivate TIMP-1 expression in pluripotent $\mathrm{C} 2 \mathrm{C} 12$ cells, suggesting that two distinct signaling molecules might together promote terminal differentiation in osteoblasts.

\section{ACKNOWLEDGMENTS}

This study was supported in part by the Japan Ministry of Education, Culture, Sports, Science and Technology Grants-in-aid 16390529 (MT).

\section{REFERENCES}

1. N. Ortega, D. J. Behonick \& Z. Werb: Matrix remodeling during endochondral ossification. Trends Cell Biol 14, 86-93 (2004)

2. M. F. Young: Bone matrix proteins: their function, regulation, and relationship to osteoporosis. Osteoporos Int 14, S35-42 (2003)

3. R. Visse \& H. Nagase: Matrix metalloproteinases and tissue inhibitors of metalloproteinases: structure, function, and biochemistry. Circ Res 92, 827-839 (2003)

4. E. Lambert, E. Dasse, B. Haye \& E. Petitfrere: TIMPs as multifacial proteins. Crit Rev Oncol Hematol 
49, 187-198 (2004)

5. K. Kusano, C. Miyaura, M. Inada, T. Tamura, A. Ito, H. Nagase, K. Kamoi \& T. Suda: Regulation of matrix metalloproteinases (MMP-2, $-3,-9$, and -13 ) by interleukin-1 and interleukin-6 in mouse calvaria: association of MMP induction with bone resorption. Endocrinology 139, 1338-1345 (1998)

6. K. Holmbeck, P. Bianco, J. Caterina, S. Yamada, M. Kromer, S. A. Kuznetsov, M. Mankani, P. G. Robey, A. R. Poole, I. Pidoux, J. M. Ward \& H. Birkedal-Hansen: MT1-MMP-deficient mice develop dwarfism, osteopenia, arthritis, and connective tissue disease due to inadequate collagen turnover. Cell 99, 81-92 (1999)

7. C. Filanti, G. R. Dickson, D. Di Martino, V. Ulivi, C. Sanguineti, P. Romano, C. Palermo \& P. Manduca: The expression of metalloproteinase-2, -9 , and -14 and of tissue inhibitors- 1 and -2 is developmentally modulated during osteogenesis in vitro, the mature osteoblastic phenotype expressing metalloproteinase-14. J Bone Miner Res 15, 2154-2168 (2000)

8. M. Uchida, M. Shima, T. Shimoaka, A. Fujieda, K. Obara, H. Suzuki, Y. Nagai, T. Ikeda, H. Yamato \& H. Kawaguchi: Regulation of matrix metalloproteinases (MMPs) and tissue inhibitors of metalloproteinases (TIMPs) by bone resorptive factors in osteoblastic cells. J Cell Physiol 185, 207-214 (2000)

9. M. D. Sternlicht \& Z. Werb: How matrix metalloproteinases regulate cell behavior. Annu Rev Cell Dev Biol 17, 463-516 (2001)

10. D. Stickens, D. J. Behonick, N. Ortega, B. Heyer, B. Hartenstein, Y. Yu, A. J. Fosang, M. Schorpp-Kistner, P. Angel \& Z. Werb: Altered endochondral bone development in matrix metalloproteinase 13-deficient mice. Development 131, 5883-5895 (2004)

11. P. Henriet, G. G. Rousseau \& Y. Eeckhout: Cloning and sequencing of mouse collagenase cDNA. Divergence of mouse and rat collagenases from the other mammalian collagenases. FEBS Lett 310, 175-178 (1992)

12. P. G. Mitchell, H. A. Magna, L. M. Reeves, L. L. Lopresti-Morrow, S. A. Yocum, P. J. Rosner, K. F. Geoghegan \& J. E. Hambor: Cloning, expression, and type II collagenolytic activity of matrix metalloproteinase-13 from human osteoarthritic cartilage. J Clin Invest 97, 761-768 (1996)

13. V. Mattot, M. B. Raes, P. Henriet, Y. Eeckhout, D. Stehelin, B. Vandenbunder \& X. Desbiens: Expression of interstitial collagenase is restricted to skeletal tissue during mouse embryogenesis. J Cell Sci 108, 529-535 (1995)

14. W. Zhao, M. H. Byrne, B. F. Boyce \& S. M. Krane: Bone resorption induced by parathyroid hormone is strikingly diminished in collagenase-resistant mutant mice. J Clin Invest 103, 517-524 (1999)

15. S. Varghese, M. L. Ramsby, J. J. Jeffrey \& E. Canalis: Basic fibroblast growth factor stimulates expression of interstitial collagenase and inhibitors of metalloproteinases in rat bone cells. Endocrinology 136, 2156-2162 (1995)

16. E. Canalis, S. Rydziel, A. M. Delany, S. Varghese \& J. J. Jeffrey: Insulin-like growth factors inhibit interstitial collagenase synthesis in bone cell cultures. Endocrinology 136, 1348-1354 (1995)

17. S. Varghese, A. M. Delany, L. Liang, B. Gabbitas, J. J. Jeffrey \& E. Canalis: Transcriptional and posttranscriptional regulation of interstitial collagenase by platelet-derived growth factor $\mathrm{BB}$ in bone cell cultures. Endocrinology 137, 431-437 (1996)

18. H. Yokota, M. B. Goldring \& H. B. Sun: CITED2-mediated regulation of MMP-1 and MMP-13 in human chondrocytes under flow shear. $J$ Biol Chem 278, 47275-47280 (2003)

19. G. S. Stein, J. B. Lian \& T. A. Owen: Relationship of cell growth to the regulation of tissue-specific gene expression during osteoblast differentiation. FASEB $J 4$, 3111-3123 (1990)

20. S. K. Winchester, S. R. Bloch, G. J. Fiacco \& N. C. Partridge: Regulation of expression of collagenase- 3 in normal, differentiating rat osteoblasts. J Cell Physiol 181, 479-488 (1999)

21. N. Fratzl-Zelman, H. Glantschnig, M. Rumpler, A. Nader, A. Ellinger \& F. Varga: The expression of matrix metalloproteinase-13 and osteocalcin in mouse osteoblasts is related to osteoblastic differentiation and is modulated by 1,25-dihydroxyvitamin D3 and thyroid hormones. Cell Biol Int 27, 459-468 (2003)

22. S. Varghese, M. L. Ramsby, J. J. Jeffrey \& E. Canalis: Basic fibroblast growth factor stimulates expression of interstitial collagenase and inhibitors of metalloproteinases in rat bone cells. Endocrinology 136, 2156-2162 (1995)

23. E. Canalis, S. Rydziel, A. M. Delany, S. Varghese \& J. J. Jeffrey: Insulin-like growth factors inhibit interstitial collagenase synthesis in bone cell cultures. Endocrinology 136, 1348-1354 (1995)

24. V. Geoffroy, C. Marty-Morieux, N. Le Goupil, P. Clement-Lacroix, C. Terraz, M. Frain, S. Roux, J. Rossert \& M. C. de Vernejoul: In vivo inhibition of osteoblastic metalloproteinases leads to increased trabecular bone mass. J Bone Miner Res 19, 811-822 (2004)

25. P. S. Rowe, P. A. de Zoysa, R. Dong, H. R. Wang, K. E. White, M. J. Econs \& C. L. Oudet: MEPE, a new gene expressed in bone marrow and tumors causing osteomalacia. Genomics 67, 54-68 (2000)

26. L. D. Quarles: FGF23, PHEX, and MEPE regulation of phosphate homeostasis and skeletal mineralization. Am J Physiol Endocrinol Metab 285, E1-9 (2003)

27. L. W. Fisher \& N. S. Fedarko: Six genes expressed in bones and teeth encode the current members of the SIBLING family of proteins. Connect Tissue Res 44, 33-40 (2003)

28. L. C. Gowen, D. N. Petersen, A. L. Mansolf, H. Qi, J. L. Stock, G. T. Tkalcevic, H. A. Simmons, D. T. Crawford, K. L. Chidsey-Frink, H. Z. Ke, J. D. 
McNeish \& T. A. Brown: Targeted disruption of the osteoblast/osteocyte factor 45 gene (OF45) results in increased bone formation and bone mass. $J$ Biol Chem 278, 1998-2007 (2003)

29. J. J. Westendorf, R. A. Kahler \& T. M. Schroeder: Wnt signaling in osteoblasts and bone diseases. Gene 341, 19-39 (2004)

30. M. L. Johnson, K. Harnish, R. Nusse \& W. Van Hul: LRP5 and Wnt signaling: a union made for bone. $J$ Bone Miner Res 19, 1749-1757. (2004)

31. X. He, M. Semenov, K. Tamai \& X. Zeng: LDL receptor-related proteins 5 and 6 in Wnt/beta-catenin signaling: arrows point the way. Development 131, 1663-1677 (2004)

32. C. Y. Logan \& R. Nusse: The Wnt signaling pathway in development and disease. Annu Rev Cell Dev Biol 20, 781-810 (2004)

33. E. Canalis, A. N. Economides, E. Gazzerro: Bone morphogenetic proteins, their antagonists, and the skeleton. Endocr Rev 24, 218-235 (2003)

34. A. Yamaguchi, T. Komori \& T. Suda: Regulation of osteoblast differentiation mediated by bone morphogenetic proteins, hedgehogs, and Cbfa1. Endocr Rev 21, 393-411 (2000).

35. H. Sudo, H. A. Kodama, Y. Amagai, S. Yamamoto \& S. Kasai: In vitro differentiation and calcification in a new clonal osteogenic cell line derived from newborn mouse calvaria. J Cell Biol 96, 191-198 (1983)

36. H. Roelink \& R. Nusse: Expression of two members of the Wnt family during mouse development--restricted temporal and spatial patterns in the developing neural tube. Genes Dev 5, 381-388 (1991)

37. B. J. Gavin, J. A. McMahon \& A. P. McMahon: Expression of multiple novel Wnt-1/int-1-related genes during fetal and adult mouse development. Genes Dev 4, 2319-2332 (1990)

38. P. Reponen, C. Sahlberg, P. Huhtala, T. Hurskainen, I. Thesleff \& K. Tryggvason: Molecular cloning of murine 72-kDa type IV collagenase and its expression during mouse development. J Biol Chem 267, 7856-7862 (1992)

39. A. Okada, J. P. Bellocq, N. Rouyer, M. P. Chenard, M. C. Rio, P. Chambon \& P. Basset: Membrane-type matrix metalloproteinase (MT-MMP) gene is expressed in stromal cells of human colon, breast, and head and neck carcinomas. Proc Natl Acad Sci U S A 92, 2730-2734 (1995)

40. D. R. Edwards, P. Waterhouse, M. L. Holman \& D. T. Denhardt: A growth-responsive gene (16C8) in normal mouse fibroblasts homologous to a human collagenase inhibitor with erythroid-potentiating activity: evidence for inducible and constitutive transcripts. Nucleic Acids Res 14, 8863-8878 (1986) 41. S. Shimizu, K. Malik, H. Sejima, J. Kishi, T. Hayakawa \& O. Koiwai: Cloning and sequencing of the cDNA encoding a mouse tissue inhibitor of metalloproteinase-2. Gene 114, 291-292 (1992)

42. A. J. Celeste, V. Rosen, J. L. Buecker, R. Kriz, E.
A.Wang \& J. M. Wozney: Isolation of the human gene for bone gla protein utilizing mouse and rat cDNA clones. EMBO J 5, 1885-1890 (1986)

43. A. C. Hahnel \& G. A. Schultz: Cloning and characterization of a cDNA encoding alkaline phosphatase in mouse embryonal carcinoma cells. Clin Chim Acta 186, 171-174 (1990)

44. E. Ogawa, M. Maruyama, H. Kagoshima, M. Inuzuka, J. Lu, M. Satake, K. Shigesada \& Y. Ito: PEBP2/PEA2 represents a family of transcription factors homologous to the products of the Drosophila runt gene and the human AML1 gene. Proc Natl Acad Sci U S A 90, 6859-6863 (1993)

45. A. Hanauer \& J. L. Mandel: The glyceraldehyde 3 phosphate dehydrogenase gene family: structure of a human cDNA and of an $\mathrm{X}$ chromosome linked pseudogene; amazing complexity of the gene family in mouse. EMBO J 3, 2627-2633 (1984)

46. K. Tokunaga, H. Taniguchi, K. Yoda, M. Shimizu \& S. Sakiyama: Nucleotide sequence of a full-length cDNA for mouse cytoskeletal beta-actin mRNA. Nucleic Acids Res 14, 2829 (1986)

47. K. Tsuji, K. Uno, G. X. Zhang \& M. Tamura: Periodontal ligament cells under intermittent tensile stress regulate mRNA expression of osteoprotegerin and tissue inhibitor of matrix metalloprotease- 1 and -2 . J Bone Miner Metab 22, 94-103 (2004)

48. E. A. Wang, V. Rosen, J. S. D'Alessandro, M. Bauduy, P. Cordes, T. Harada, D. I. Israel, R. M. Hewick, K. M. Kerns, P. LaPan, D. H. Luxenberg, D. McQuid, I. K. Moutsatsos, J. Nove \& J. M. Wozney: Recombinant Human Bone Morphogenetic Protein Induces Bone Formation. Proc Natl Acad Sci U S A 87, 2220-2224 (1990)

49. T. Katagiri, A. Yamaguchi, M. Komaki, E. Abe, N. Takahashi, T. Ikeda, V. Rosen, J. M. Wozney, A. Fujisawa-Sehara \& T. Suda: Bone morphogenetic protein-2 converts the differentiation pathway of C2C12 myoblasts into the osteoblast lineage. J Cell Biol 127, 1755-1766 (1994)

50. T. Katagiri \& N. Takahashi: Regulatory mechanisms of osteoblast and osteoclast differentiation. Oral Dis 8, 147-159 (2002)

51. C. Banerjee, A. Javed, J. Y. Choi, J. Green, V. Rosen, A. J. van Wijnen, J. L. Stein, J. B. Lian \& G. S. Stein: Differential regulation of the two principal Runx2/Cbfa1 n-terminal isoforms in response to bone morphogenetic protein-2 during development of the osteoblast phenotype. Endocrinology 142, 4026-4039 (2001)

52. G. Bain, T. Muller, X. Wang \& J. Papkoff: Activated beta-catenin induces osteoblast differentiation of C3H10T1/2 cells and participates in BMP2 mediated signal transduction. Biochem Biophys Res Commun 301, 84-91 (2003)

53. S. K. Winchester, N. Selvamurugan, R. C. D'Alonzo \& N. C. Partridge: Developmental regulation of collagenase-3 mRNA in normal, differentiating osteoblasts through the activator protein- 1 and the runt 
domain binding sites. J Biol Chem 275, 23310-23318 (2000)

54. B. A. Davis, B. Sipe, L. A. Gershan, G. J. Fiacco, T. C. Lorenz, J. J. Jeffrey \& N. C. Partridge: Collagenase and tissue plasminogen activator production in developing rat calvariae: normal progression despite fetal exposure to microgravity. Calcif Tissue Int 63, 416-422 (1998)

55. E. Y. Liao, X. H. Luo, X. G. Deng \& X. P. Wu: Effects of 17beta-estradiol on the expression of membrane type 1 matrix metalloproteinase (MT1-MMP) and MMP-2 in human osteoblastic MG-63 cell cultures. J Endocrinol Invest 24, 876-881 (2001)

56. S. Bord, A. Horner, C. A. Beeton, R. M. Hembry \& J. E. Compston: Tissue inhibitor of matrix metalloproteinase-1 (TIMP-1) distribution in normal and pathological human bone. Bone 24, 229-235 (1999) 57. G. X. Zhang, M. Mizuno, K. Tsuji \& M. Tamura: Regulation of mRNA expression of matrix extracellular phosphoglycoprotein (MEPE)/ osteoblast/osteocyte factor 45 (OF45) by fibroblast growth factor 2 in cultures of rat bone marrow-derived osteoblastic cells. Endocrine 24, 15-24 (2004)

58. E. Labbe, A. Letamendia \& L. Attisano: Association of Smads with lymphoid enhancer binding factor $1 / \mathrm{T}$ cell-specific factor mediates cooperative signaling by the transforming growth factor-beta and wnt pathways. Proc Natl Acad Sci U S A 97, 8358-8363 (2000)

59. S. Iwasaki, M. Iguchi, K. Watanabe, R. Hoshino, M. Tsujimoto \& M. Kohno: Specific activation of the p38 mitogen-activated protein kinase signaling pathway and induction of neurite outgrowth in PC12 cells by bone morphogenetic protein-2. J Biol Chem 274, 26503-26510 (1999)

Abbreviations: ECM: extracellular matrix; BMP: bone morphogenetic protein; ALP: alkaline phosphatase; MMP: matrix metalloprotease; TIMP: tissue inhibitor of matrix metalloprotease; MT1-MMP: membrane type-1 matrix metalloproteinases; MEPE: matrix extracelluer phosphoglycoprotein

Key Words:

Matrix Metalloproteinase, TIMP, Wnt3a, Bone Morphogenetic Protein-2, Osteoblast

Send Correspondence to: Dr. Masato Tamura, Department of Biochemistry and Molecular Biology, Graduate School of Dental Medicine, Hokkaido University, North 13, West 7, Sapporo, 060-8586, Japan Tel; 011-81-11-706-4231, Fax; 011-81-11-706-4877

E-mail; mtamura@den.hokudai.ac.jp

Running title:

Wnt3a and BMP-2 regulate MMP-13 mRNA expression
A

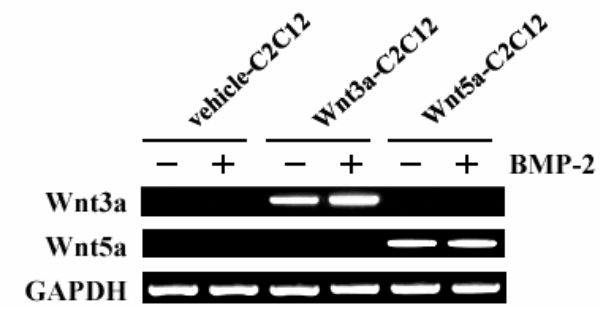

B

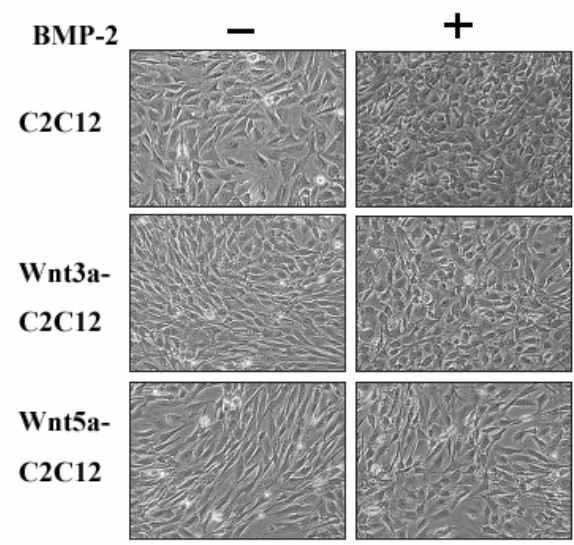

Figure 1.

Establishment and characterization of Wnt3a or Wnt5a stably expressing C2C12 cells. C2C12 cells were transfected with $1.0 \quad \mu \mathrm{g}$ of Wnt3a-pUSEamp, Wnt5a-pUSEamp or empty vector and then transfected cell clones (Wnt3a-C2C12, Wnt5a-C2C12 or vehicle-C2C12 cells) were selected. Cells were plated at $1 \mathrm{X} 10^{5} \mathrm{cells} / \mathrm{cm}^{2}$ in $100 \mathrm{~mm}$ cell culture dishes and cultured for $24 \mathrm{~h}$. Then, $300 \mathrm{ng} / \mathrm{ml}$ of bone morphogenetic protein (BMP) $(+)$ or vehicle (-) was added in $\alpha$-MEM supplemented with $10 \%$ FBS, after which cells were cultured for a further $24 \mathrm{~h}$. Total cellular RNA was extracted and RT-PCR was performed to estimate the level of Wnt3a or Wnt5a mRNA expression (A). The PCR products were separated on a $2 \%$ agarose gel containing ethidium bromide, and then observed on an ultraviolet transilluminator. Equal loading of cDNA samples was confirmed by amplification of glucose-6-phosphate dehydrogenase (GAPDH) cDNA. These data represent one of three independent experiments with similar results. Cell morphology viewed by phase contrast microscopy (B). Magnification: X100. 

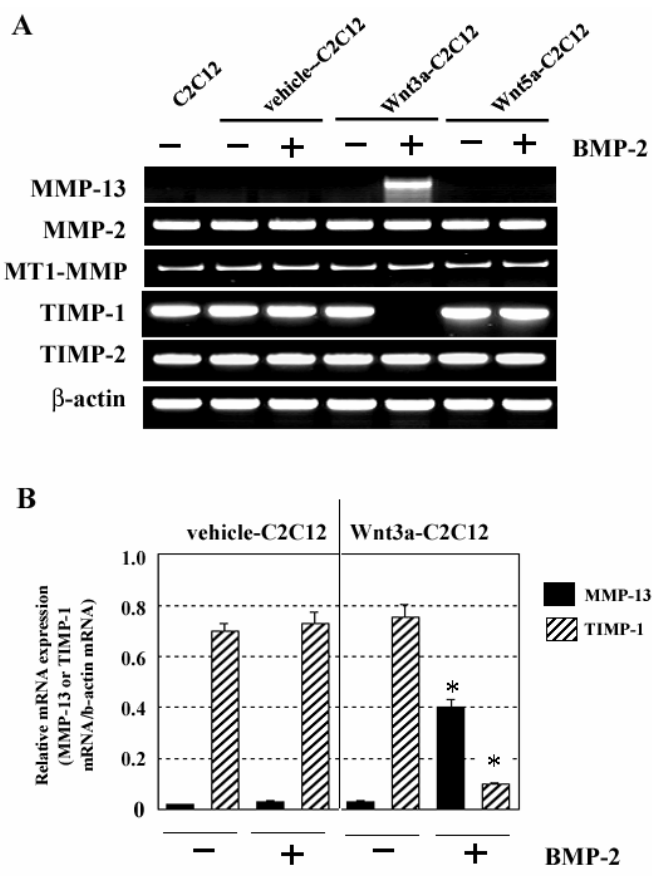

Figure 2.

Matrix metalloproteinase (MMP) and tissue inhibitor of matrix metalloproteinase (TIMP) mRNA expressions and their regulation by BMP-2 in Wnt3a-C2C12, Wnt5a-C2C12 or vehicle-C2C12 cells. Wnt3a-C2C12, Wnt5a-C2C12, vehicle-C2C12 or control C2C12 cells were plated at $1 \mathrm{X} 10^{5}$ cells $/ \mathrm{cm}^{2}$ in $100 \mathrm{~mm}$ cell culture dishes and cultured for $24 \mathrm{~h}$. Then, $300 \mathrm{ng} / \mathrm{ml}$ of BMP-2 (+) or vehicle (-) was added, after which cells were cultured for a further $24 \mathrm{~h}$. Total RNA was extracted from the cells and the mRNA expression levels of matrix metalloproteinase (MMP)-13, MMP-2, membrane type-1 matrix metalloproteinases (MT1-MMP), tissue inhibitor of matrix metalloproteinase (TIMP)-1 or TIMP-2 were determined by RT-PCR (A) and quantitative real time PCR (B) as described in Materials and Methods. Agarose gel electrophoresis showing the amplification products of MMP-13, MMP-2, MT1-MMP, TIMP-1 or TIMP-2 cDNAs (A). The data represent one of three experiments with similar results. Ratio of MMP-13 or TIMP-1 mRNA to $\beta$-actin mRNA copies measured by quantitative real time PCR (B). The results shown are the mean $\pm \mathrm{SD}$ of three independent experiments. * Significant difference from BMP-2 (-) culture $(P<0.05)$ : ANOVA, Student's $t$-test.

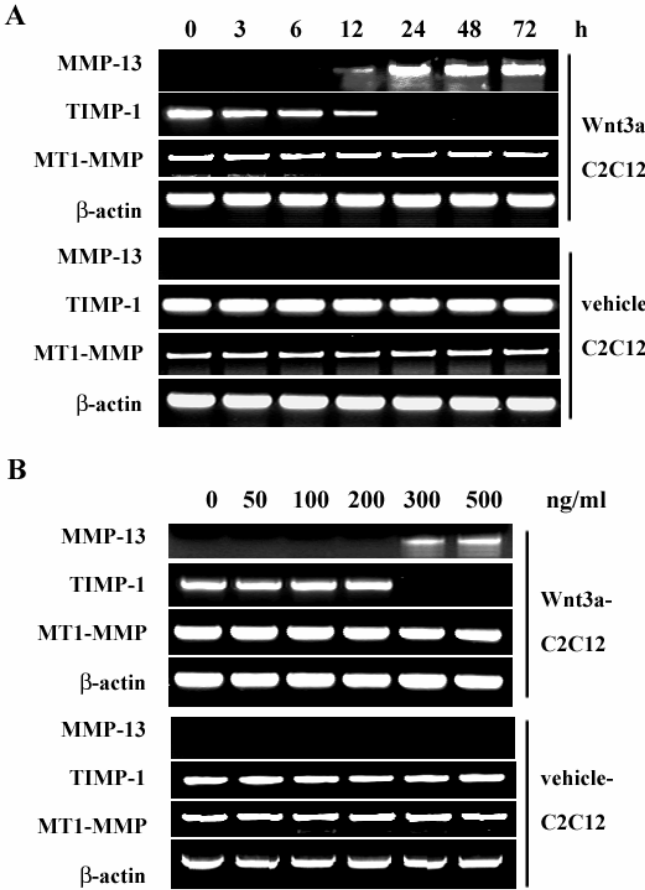

Figure 3.

Time and dose dependent regulation of mRNA expression of MMP-13 or TIMP-1 with the addition of BMP-2 in Wnt3a-C2C12 cells. Wnt3a-C2C12 cells were plated at $1 \mathrm{X} 10^{5}$ cells $/ \mathrm{cm}^{2}$ in $100 \mathrm{~mm}$ cell culture dishes. After $24 \mathrm{~h}$, the medium was changed and 300 $\mathrm{ng} / \mathrm{ml}$ (A) or indicated concentrations (B) of BMP-2 was added, after which cells were cultured for a further indicated time (A) or $24 \mathrm{~h}$ (B). RT-PCR analysis was performed as described in Materials and Methods. The data represent one of three experiments with similar results.

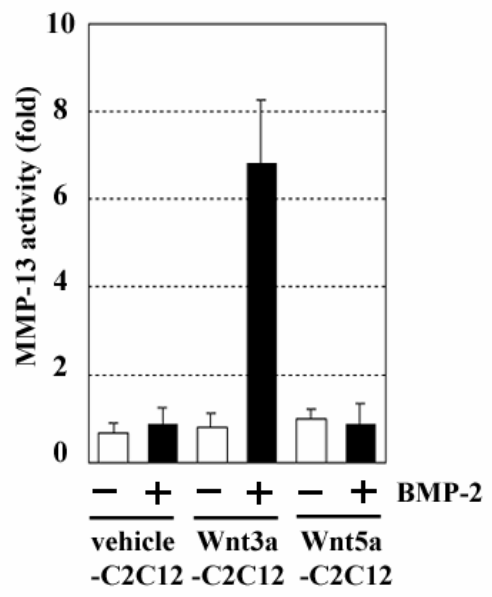


Figure 4.

MMP-13 activity and their regulation by BMP-2 in Wnt3a-C2C12, Wnt5a-C2C12 or vehicle-C2C12 cells. Wnt3a-C2C12 cells, Wnt5a-C2C12 cells and vehicle-C2C12 cells were seeded at the density of $1 \mathrm{X} 10^{6}$ cells on a $100-\mathrm{mm}$ cell culture dish in $10 \mathrm{ml}$ of culture medium and cultured for $24 \mathrm{~h}$. Then, $300 \mathrm{ng} / \mathrm{ml}$ of BMP-2 (+) or vehicle (-) was added in $\alpha$-MEM supplemented with $10 \%$ FBS, after which cells were cultured for $48 \mathrm{~h}$. After medium was changed to serum-free $\alpha$-MEM with $300 \mathrm{ng} / \mathrm{ml}$ of BMP-2, cells were cultured for a further $24 \mathrm{~h}$. Then, the culture supernatant of each dish was collected and MMP-13 activity was determined using synthetic fluorogenic peptide as described in the Materials and Methods. MMP-13 activity is represented as fold induction over vehicle-C2C12 cells without BMP-2. All samples were assayed in triplicate. Data are means \pm s.d. $(n=3)$.

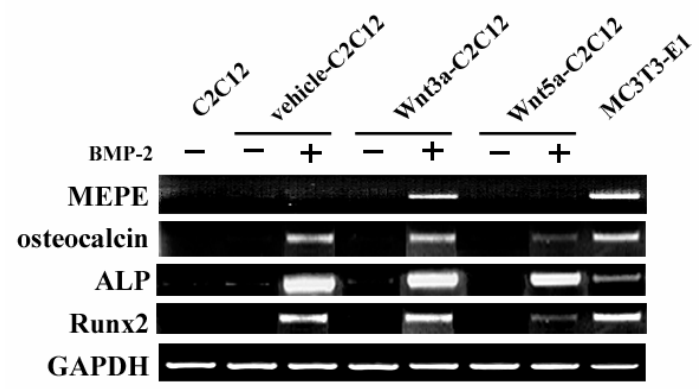

Figure 5.

Matrix extracellular phosphoglycoprotein (MEPE), osteocalcin, alkaline phosphatase (ALP) and Runx2 mRNA expression and their regulation by BMP-2 in Wnt3a-C2C12, Wnt5a-C2C12 or vehicle-C2C12 cells. Wnt3a-C2C12, Wnt5a-C2C12, vehicle-C2C12 cells, control C2C12 cells or MC3T3-E1 cells were plated at $1 \mathrm{X} 10^{5}$ cells $/ \mathrm{cm}^{2}$ in $100 \mathrm{~mm}$ cell culture dishes and cultured for $24 \mathrm{~h}$. Then, $300 \mathrm{ng} / \mathrm{ml}$ of BMP-2 (+) or vehicle (-) was added, after which cells were cultured for a further $24 \mathrm{~h}$. Total cellular RNA was extracted and then RT-PCR was performed to estimate the level of MEPE, osteocalcin, ALP or Runx2 mRNA expression as described in Materials and Methods and the legend of Figure 1. The data represent one of three experiments with similar results.
A

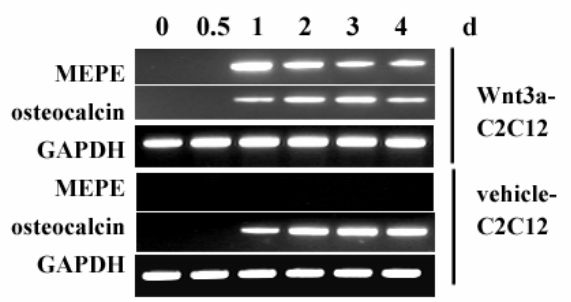

B

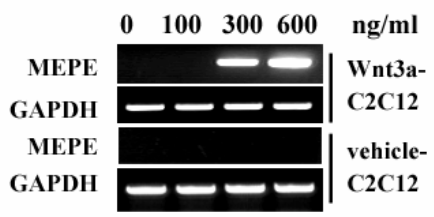

C

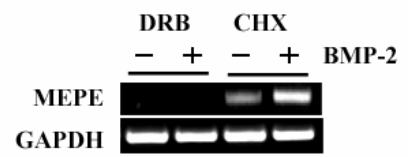

Figure 6.

Time and dose dependent induction of MEPE mRNA expression with the addition of BMP-2

inWnt3a-C2C12 cells. Wnt3a-C2C12 cells were plated at $1 \mathrm{X} 10^{5}$ cells $/ \mathrm{cm}^{2}$ in $100 \mathrm{~mm}$ cell culture dishes. After 24h, the medium was changed and $300 \mathrm{ng} / \mathrm{ml}$ (A) or indicated concentrations (B) of BMP-2 was added, after which cells were cultured for a further indicated day (A) or $24 \mathrm{~h}$ (B). RT-PCR analysis was performed as described in Materials and Methods and the legend of Figure 1. The data represent one of three experiments with similar results. Wnt3a-C2C12 cells were plated at $1 \mathrm{X} 10^{5}$ cells $/ \mathrm{cm}^{2}$ in $100 \mathrm{~mm}$ cell culture dishes. After $24 \mathrm{~h}$, the cells were cultured for a further $24 \mathrm{~h}$ with 300 $\mathrm{ng} / \mathrm{ml} \mathrm{BMP-2}$ in the presence or absence of $10 \mu \mathrm{g} / \mathrm{ml}$ of dichlororibofuranosyl benzimidazole (DRB) or $5 \mu \mathrm{g} / \mathrm{ml}$ of cycloheximide (CHX). Then, total cellular RNA was isolated, and RT-PCR analysis was performed (C). 
Wnt3a and BMP-2 regulate MMP-13 mRNA expression

Table 1. Primers used for RT-PCR

\begin{tabular}{|c|c|c|c|c|}
\hline Specificity & Oligonucleotide sequence (5’-3’') & $\begin{array}{l}\text { Anneal. } \\
\text { Temp. ( } \\
\left.{ }^{\circ} \mathrm{C}\right)\end{array}$ & $\begin{array}{l}\text { Predicted size } \\
\text { (bp) }\end{array}$ & Ref \\
\hline Wnt3a & $\begin{array}{l}\text { ATTGAATTTGGAGGAATGGT } \\
\text { CTTGAAGTACGTGTAACGTG }\end{array}$ & 52 & 318 & 36 \\
\hline Wnt5a & $\begin{array}{l}\text { TCCTATGAGAGCGCACGCAT } \\
\text { CAGCTTGCCCCGGCTGTTGA }\end{array}$ & 60 & 236 & 37 \\
\hline MMP-13 & $\begin{array}{l}\text { CTTCTGGTCTTCTGGCACAC } \\
\text { CCCСACСССАTACATCTGAA }\end{array}$ & 53 & 942 & 11 \\
\hline MMP-2 & $\begin{array}{l}\text { AGATCTTCTTCTTCAAGGACCGGTT } \\
\text { GGCTGGTCAGTGGCTTGGGGTA }\end{array}$ & 51 & 204 & 38 \\
\hline MT1-MMP & $\begin{array}{l}\text { TTGATTCTGCCGAGCCCTGGACT } \\
\text { GTCTCCTCCTCAGTCCCCTCAT }\end{array}$ & 53 & 801 & 39 \\
\hline TIMP-1 & $\begin{array}{l}\text { GACCACCTTATACCAGCGTT } \\
\text { GTCACTCTCCAGTTTGCAAG }\end{array}$ & 52 & 321 & 40 \\
\hline TIMP-2 & $\begin{array}{l}\text { GAGCCAAAGCAGTGAGCGAGAA } \\
\text { GGGGAGGAGATGTAGCAAGGGA }\end{array}$ & 55 & 370 & 41 \\
\hline MEPE & $\begin{array}{l}\text { GTCGTCATCCAGTGGGAGTT } \\
\text { TAATGTGTCGCCTGTCCAAA }\end{array}$ & 55 & 235 & 32 \\
\hline Osteocalcin & $\begin{array}{l}\text { CTGAGTCTGACAAAGCCTTC } \\
\text { GCTGTGACATCCATACTTGC }\end{array}$ & 55 & 312 & 42 \\
\hline ALP & $\begin{array}{l}\text { ATTGCCCTGAAACTCCAAAACC } \\
\text { CCTCTGGTGGCATCTCGTTATC }\end{array}$ & 55 & 470 & 43 \\
\hline Runx2 & $\begin{array}{l}\text { AGCAACAGCAACAACAGCAG } \\
\text { GTAATCTGACTCTGTCCTTG }\end{array}$ & 57 & 664 & 44 \\
\hline GAPDH & $\begin{array}{l}\text { ACCACAGTCCATGCCATCAC } \\
\text { TCCACCACCCTGTTGCTGTA } \\
\end{array}$ & 58 & 452 & 45 \\
\hline$\beta$-actin & $\begin{array}{l}\text { CACCCTGTGCTGCTCACCGAGGCC } \\
\text { CCACACAGAGTACTTGCGCTCAGG }\end{array}$ & 55 & 729 & 46 \\
\hline
\end{tabular}

MMP, matrix metalloproteinase; MT1-MMP, membrane type-1 matrix metalloproteinase; TIMP, tissue inhibitor of matrix metalloproteinase; MEPE: matrix extracelluer phosphoglycoprotein; ALP, alkaline phosphatase; GAPDH, glyceraldehyde-3-phosphate dehydrogenase 